\title{
A Consistency Check Method for Trusted Hesitant Fuzzy Sets with Confidence Levels Based on a Distance Measure
}

\author{
Huimin Xiao $(\mathbb{D}$, Meiqi Wang, and Xiaoning Xi \\ Henan University of Economics and Law, Zhengzhou 450046, China \\ Correspondence should be addressed to Huimin Xiao; xiaohm@huel.edu.cn
}

Received 11 June 2020; Revised 26 July 2020; Accepted 28 July 2020; Published 27 October 2020

Guest Editor: Tingqiang Chen

Copyright (C) 2020 Huimin Xiao et al. This is an open access article distributed under the Creative Commons Attribution License, which permits unrestricted use, distribution, and reproduction in any medium, provided the original work is properly cited.

\begin{abstract}
This paper proposes a consistency check method for hesitant fuzzy sets with confidence levels by employing a distance measure. Firstly, we analyze the difference between each fuzzy element and its corresponding attribute comprehensive decision value and then obtain a comprehensive distance measure for each attribute. Subsequently, by taking the relative credibility as the weight, we assess the consistency of hesitant fuzzy sets. Finally, numerical examples are put forward to verify the effectiveness and reliability of the proposed method.
\end{abstract}

\section{Introduction}

As a generalization of fuzzy set (FS), hesitant fuzzy set (HFS) has attracted much attention since it was proposed by Torra [1] in 2010. The greatest advantage of hesitant fuzzy set (HFS) is to extend the membership degree of fuzzy set (FS) from a specific number to a set. This makes hesitant fuzzy sets have more advantages in dealing with uncertainties caused by hesitation in reality. In recent years, many scholars have introduced the concept of credibility into hesitant fuzzy sets, which makes the advantages of hesitant fuzzy sets more prominent, considering that decision makers have different familiarity with different professional fields. For uncertain fuzzy sets with credibility, Xia et al. [2] proposed a confidence-induced uncertain weighted average (CIHFWA) operator. Ruan et al. [3] further proposed the concept of relative credibility, and based on this, they proposed the relative credibility induced hesitation fuzzy ordered weighted average (RCIHFOWA) operator. Based on these algorithms, many scholars have also obtained a series of effective multiattribute decision-making methods based on credibility through research.

Consistency testing is an important work in multiattribute group decision making, aiming at identifying those expert opinions which differ greatly from group opinions, providing theoretical basis and data to support for modifying and eliminating these "nongroup" opinions, and thus ensuring the consistency of group opinions. There are many studies on the consistency of multiattribute group decision making, such as group consistency based on reciprocal judgment matrix, complementary judgment matrix, and linguistic judgment matrix. The corresponding methods of group consistency analysis are proposed in [4-11]. Xu et al. [12] used a consistency test method to test interval fuzzy preference relation. In [13-15], the consistency of interval number decision matrix, linguistic decision matrix, and real number decision matrix in multiattribute group decision making is studied, respectively.

Consistency check is widely used in multiattribute decision making, but there are few studies on consistency check based on hesitation fuzzy set. The unique structure characteristic of hesitation fuzzy set not only gives it many advantages but also means that it is necessary to establish its own index system and decision-making method. The hesitation fuzzy set contains a lot of hesitation fuzzy elements, which makes the information integration method more complex, so the application of consistency check in the hesitation fuzzy set is particularly important.

In this paper, a consistency checking method based on distance measure is proposed for uncertain fuzzy sets with credibility. When analyzing the consistency of hesitant fuzzy sets, this method integrates information through some integration operators of hesitant fuzzy sets and obtains the 
comprehensive decision values of attributes after information integration. Then, the initial distance measure corresponding to each attribute is obtained by using relative credibility, and it is used as an index to judge consistency. Indicators that do not satisfy consistency can optimize the data by adjusting the credibility, and then a hesitant fuzzy decision matrix that satisfies the consistency condition can be obtained.

Because the differences of membership degree among hesitant fuzzy elements are fully taken into account in distance measure, the measure is suitable to be used as an index to judge consistency. In recent years, distance measure has been used in the fields of high-order hesitant fuzzy sets [16], dual hesitant fuzzy sets [17], and hesitant fuzzy information [18]. In this paper, the existing distance measure method [19-22] is improved, and a new weighted distance measure based on relative reliability is obtained, which is applied to the consistency test. There are also some recent research results [23-25] which study the application of HFSs under different situations.

The innovations of this paper are as follows:

(1) A weighted distance considering relative reliability is introduced.

(2) A consistency check method by using integration operators is proposed, which includes a feedback process for the decision makers.

\section{Relevant Theory of Hesitant Fuzzy Set}

Torra [1] proposed the concept of hesitant fuzzy set, which is generally described as follows.

Definition 1 (see [1]). If there is a nonempty set $X=\left\{x_{1}, x_{2}, \ldots, x_{n}\right\}$, the hesitant fuzzy set is a function of a finite subset from $X=\left\{x_{1}, x_{2}, \ldots, x_{n}\right\}$ to $[0,1]$, which can be expressed by the following mathematical formula:

$$
E=\left\{<x, h_{E}(x)>\mid x \in X\right\},
$$

where $h_{E}(x)$ denotes a set of possible membership values belonging to $[0,1]$ and $x \in X$ denotes a set of membership degrees belonging to $E$.

The length of fuzzy numbers given by experts is different when solving problems, and there are many ways to make up, and we choose the most reliable way to make up: in the shorter number, select the evaluation with the highest credibility value in the hesitant fuzzy number and add this value to the original data until the value is the same as the standard value.

In 2011, Xia et al. [2] gave some basic operation rules based on hesitant fuzzy sets according to the operation rules of intuitionistic fuzzy sets.

(1) $h^{\lambda}=\cup_{\gamma \in h}\left\{\gamma^{\lambda}\right\}$

(2) $\lambda h=\cup_{\gamma \in h}\left\{1-(1-\gamma)^{\lambda}\right\}$

(3) $h_{1} \oplus h_{2}=\cup_{\gamma_{1} \in h_{1}, \gamma_{2} \in h_{2}}\left\{\gamma_{1}+\gamma_{2}-\gamma_{1} \gamma_{2}\right\}$

(4) $h_{1} \otimes h_{2}=\cup_{\gamma_{1} \in h_{1}, \gamma_{2} \in h_{2}}\left\{\gamma_{1} \gamma_{2}\right\}$

Considering the influence of credibility on hesitation fuzzy sets, Xia et al. [2] gave a class of confidence-induced hesitation fuzzy weighting operators.
Suppose that there exists a set of hesitant fuzzy sets $h_{1}, h_{2}, \ldots, h_{n}$; then,

$$
\begin{aligned}
& \operatorname{CIHFWA}\left(h_{1}, h_{2}, \ldots, h_{n}\right)=\underset{i=1}{\oplus} w_{i}\left(l_{i} h_{i}\right) \\
& =\cup_{\gamma_{1} \in h_{1}, \gamma_{2} \in h_{2}, \ldots, \gamma_{n} \in h_{n}}\left(1-\prod_{i=1}^{n}\left(1-\left(l_{i} \gamma_{i}\right)\right)^{w_{i}}\right),
\end{aligned}
$$

where $l_{i} \in[0,1]$ is the expert credibility corresponding to $h_{i}(i=1,2, \ldots, n), \quad \forall \gamma_{i} \in h_{i}, w=\left(w_{1}, w_{2}, \ldots, w_{n}\right)^{T}$ is the weight vector corresponding to $h_{i}(i=1,2, \ldots, n)$, $w_{i} \in[0,1]$, and $\sum_{i=1}^{n} w_{i}=1$. It is called a confidence-induced hesitation fuzzy weighted average (CIHFWA) operator.

This confidence-based aggregator considers absolute credibility. In 2016, Ruan et al. [3] proposed the concept of relative credibility and gave the relative confidence-induced hesitant fuzzy ordered weighted averaging (RCIHFOWA) operator.

Definition 2 (see [3]). For hesitant fuzzy numbers $h_{1}, h_{2}, \ldots, h_{n}$ and RCIHFOWA: $\Omega_{n} \longrightarrow \Omega$, if

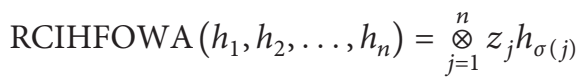

$$
\begin{aligned}
& =\cup_{\gamma_{\sigma(j)} \in h_{\sigma(j)}}\left(1-\prod_{j=1}^{n}\left(1-\gamma_{\sigma(j)}\right)^{z_{j}}\right),
\end{aligned}
$$

then RCIHFOWA is called a relative confidence-induced hesitation fuzzy ordered weighted averaging operator.

In equation (3), $Z=\left(Z_{1}, Z_{2}, \ldots, Z_{n}\right)^{T}$ is the weight vector associated with RCIHFOWA operator, which is defined as follows:

$$
Z_{j}=\frac{w_{j} \times y_{j}}{\sum_{j=1}^{n} w_{j} \times y_{j}}, \quad(j=1,2, \ldots, n),
$$

where $y_{j}$ is the reliability coefficient, $y_{j}=l_{j} / \sum_{j=1}^{n} l_{j}$, $0 \leq l_{j} \leq 1$ is the reliability, $h_{\sigma(j)}$ is the element of the largest $j$ in the hesitant fuzzy number $h_{j}(j=1,2, \ldots, n), w_{j}$ is the position weight of $h_{\sigma(j)}$, and $(\sigma(1), \sigma(2), \ldots, \sigma(n))$ is a permutation of $(1,2, \ldots, n)$. For any $j$, it satisfies $h_{\sigma(j-1)} \geq h_{\sigma(j)}$.

The concept of a distance measure of hesitant fuzzy sets is given as follows:

Definition 3 (see [19]). Suppose that $U$ is a nonempty set, $M, N, O \in H F(U)$, and $d$ is a distance measure of a hesitant fuzzy set if the following properties hold:

(1) $0 \leq d(M, N) \leq 1$

(2) $d(M, N)=0$, if and only if, $M=N$

(3) $d(M, N)=d(N, M)$ follows:

The generalized hesitation weighted distance is given as 


$$
d_{w g}(F, G)=\left[\sum_{i=1}^{n} \omega_{i}\left(\frac{1}{m_{i}} \sum_{j=1}^{m_{i}}\left|h_{F}\left(x_{i}\right)^{\sigma(j)}-h_{F}\left(x_{i}\right)^{\sigma(j)}\right|^{\lambda}\right)\right]^{1 / \lambda},
$$

where $\omega_{i} \geq 0, \sum_{i=1}^{n} \omega_{i}=1, m_{i}=\max \left\{\left|h_{F}\left(x_{i}\right)\right|,\left|h_{G}\left(x_{i}\right)\right|\right\}$, and $\left|h_{F}\left(x_{i}\right)\right|$ and $\left|h_{G}\left(x_{i}\right)\right|$ represent the number of elements contained in $F\left(x_{i}\right)$ and $G\left(x_{i}\right)$, respectively.

\section{A Consistency Check Method for Trusted Hesitant Fuzzy Sets with Confidence Levels Based on a Distance Measure}

From the relevant theory, different ideas can be used in the consistency check of hesitant fuzzy sets.

Here, suppose that $A=\left\{A_{1}, A_{2}, \ldots, A_{m}\right\}$ is a scheme set, $G=\left\{G_{1}, G_{2}, \ldots, G_{n}\right\}_{T} \quad$ is an attribute set, and $Z=\left\{Z_{1}, Z_{2}, \ldots, Z_{p}\right\}$ is a weight vector of the fuzzy element. The expert group measures the index $G_{i} \in G$ of scheme $A_{i} \in A$ and eliminates duplicate data, thus forming a reliable hesitant fuzzy evaluation matrix $D_{m \times n \times p}=\left(h_{i j k}\right)_{m \times n \times p}$, and then we standardize the reliable hesitant fuzzy evaluation matrix, suppose the most credible number $h_{i j k}$ in $h_{i j}$ named $h_{i j k}^{\prime}$, then expanding $h_{i j k}^{\prime}$ to $h_{i j}$, in order to standardize each hesitant fuzzy number into equal length data. The standardized matrix is recorded as $D^{\prime}$. The evaluation matrix used in the following calculations is $D^{\prime} . p$ is the number of fuzzy numbers in the attribute, $h_{i j k}$ represents the $k$-th hesitant fuzzy number of the $j$ attribute of scheme $i$, and $l_{i j k} \in[0,1]$ is the expert credibility corresponding to the hesitant fuzzy number $h_{i j k}$. From the basic definition of distance measure, the following conclusions can be easily drawn.

LEt that the credibility hesitant fuzzy evaluation matrix given by expert group named $D_{m \times n \times p}=\left(h_{i j k}\right)_{m \times n \times p}$ and named the standarized matrix as $D^{\prime}$, and the comprehensive decision matrix of attributes after information integration within attributes is $D_{m \times n}^{\prime}=\left(h_{i j}\right)_{m \times n}$; then,

$$
\bar{d}_{z g}\left(h_{i \times j}, h_{i \times j \times p}\right)=\left(\sum_{k=1}^{p} z_{k}\left|h_{i j}-h_{i j k}\right|^{\lambda}\right)^{1 / \lambda},
$$

is called the relative reliability weight difference of $j$ attribute of $i$ scheme, and $z_{k}$ is the relevant weight (equation (4)). It is easy to prove that $\bar{d}_{z g}\left(h_{i \times j}, h_{i \times j \times p}\right)$ has the following properties:

(1) $0 \leq \bar{d}_{z g}\left(h_{i \times j}, h_{i \times j \times p}\right) \leq 1$

(2) $\bar{d}_{z g}\left(h_{i \times j}, h_{i \times j \times p}\right)=\bar{d}_{z g}\left(h_{i \times j \times p}, h_{i \times j}\right)$, $\bar{d}_{z g}\left(h_{i \times j}, h_{i \times j \times p}\right)=0$, if and only if, $h_{i \times j}=h_{i \times j \times p}$

(3) $\bar{d}_{z g}\left(h_{i \times j}, h_{i \times j \times p}\right)=1$, if and only if, $h_{i \times j}$ is completely unrelated to $h_{i \times j \times p}$.

Meanwhile, assume that the trustworthy hesitant fuzzy evaluation matrix given by expert group is $D_{m \times n \times p}=\left(h_{i j k}\right)_{m \times n \times p}$, the normalized matrix is calculated to be $D^{\prime}$, and the integrated decision matrix of attributes after information integration within attributes is $D_{m \times n}^{\prime}=\left(h_{i j}\right)_{m \times n}$. If

$$
\bar{d}_{z g}\left(h_{i \times j}, h_{i \times j \times p}\right)<\alpha,
$$

holds, then we call $h_{i \times j}$ and $h_{i \times j \times p}$ have acceptable difference, and $\alpha$ is the threshold of acceptable difference.

In practical problems, different thresholds can be selected according to the actual situation. When the difference degree meets the threshold condition, we believe that the hesitant fuzzy set provided by the expert group meets the consistency. When the difference degree does not meet the threshold condition, i.e., case $\bar{d}_{z g}\left(h_{i \times j}, h_{i \times j \times p}\right)>\alpha, h_{i \times j \times p}$ should be returned to the expert group. At the same time, it is analyzed which fuzzy element in the hesitant fuzzy decision matrix increases the difference degree. The expert group is then required to make a new decision until $\bar{d}_{z g}\left(h_{i \times j}, h_{i \times j \times p}\right)$ meets the threshold condition, i.e., until the consistency condition is satisfied.

The difference degree $\bar{d}_{z g}\left(h_{i \times j}, h_{i \times j \times p}\right)$ reflects the difference degree between the internal elements of each attribute and the comprehensive decision value of the attribute and also reflects the decision level of the decision matrix provided by the decision expert group. In many practical problems, each expert in the decision expert group may be hesitant to provide too high or too low fuzzy preference data when evaluating the object of his hobby or boredom, which leads to the high degree of difference between the decision elements within the attribute and the integrated attribute comprehensive decision value. If this case happens, we should consider adjusting the credibility of these abnormal decisionmaking values in the specific decision-making process to reduce the credibility of those fuzzy elements with too high degree of difference. In view of this situation, a method of reliability regulation can be given:

$$
l_{i j k}^{\prime}=\frac{\left.\bar{d}_{z g}\left(h_{i \times j}, h_{i \times j \times p}\right)\right|_{\lambda=1}}{\left|h_{i j}-h_{i j k}\right|} \times l_{i j k}, \quad\left(\left|h_{i j}-h_{i j k}\right| \neq 0\right) .
$$

In particular, according to the definition of credibility, when the adjusted $l_{i j k}^{\prime}$ is greater than 1 , the maximum $l_{i j k}^{\prime}=1$ of credibility is taken.

Equation (8) can effectively reduce the credibility of those fuzzy elements with high degree of difference or improve the credibility of low degree of difference fuzzy elements.

\section{Method Implementation}

The concrete steps of the consistency test method of hesitant fuzzy decision matrix based on credibility and distance measure proposed above are as follows:

Step 1: consider a multiattribute decision-making problem in the form of incomplete attribute priority and uncertain fuzzy decision matrix with credibility. Let $A=\left\{A_{1}, A_{2}, \ldots, A_{m}\right\}$ be the scheme set and $G=\left\{G_{1}, G_{2}, \ldots, G_{n}\right\}$ be the attribute set. The expert group measures the index $G_{i} \in G$ of scheme $A_{i} \in A$ and eliminates duplicate data, thus constituting a reliable hesitant fuzzy evaluation matrix $D_{m \times n \times p}=\left(h_{i j k}\right)_{m \times n \times p}$, 
and the corresponding credibility of each hesitant fuzzy number is the initial credibility. The standardized matrix is recorded as $D^{\prime}$. The evaluation matrix used in the following calculations is $D^{\prime}$.

Step 2: use the trustworthy hesitant fuzzy ensemble operator (such as CIHFWA) to aggregate the corresponding trustworthy hesitant fuzzy numbers of each attribute and obtain the comprehensive decision values of each attribute of each scheme. The trustworthy hesitant fuzzy elements and corresponding attributes of each attribute are calculated by equation (6) and the difference between the decision values are synthesized.

Step 3: assuming that the expert group gives the threshold $\alpha$ of association degree in advance, if $\bar{d}_{z g}\left(h_{i \times j}, h_{i \times j \times p}\right)<\alpha$, it will have satisfactory consistency; otherwise, equation (8) should be used to appropriately modify the credibility of the hesitant fuzzy element in the attribute and feed back the hesitant fuzzy element of the attribute and the comprehensive decision value of the attribute to the expert group. At the same time, the expert group is informed which hesitant fuzzy elements had a high degree of difference, and the expert group is asked to re-evaluate the credibility of the relevant hesitant fuzzy elements. Repeat the process until there is an acceptable difference, $\bar{d}_{z g}\left(h_{i \times j}, h_{i \times j \times p}\right)<\alpha$. At this time, the decision matrix satisfies the consistency check.

\section{Case Analysis}

The consistency check method for trusted hesitant fuzzy set with confidence level based on distance measure can be applied to multiattribute group decision-making problems such as project cost, market analysis, road traffic, resource allocation, and quality assessment. By checking the consistency of the hesitation fuzzy set and correcting the data that do not meet the consistency test, the hesitation fuzzy decision matrix that meets the consistency condition is obtained, and then the decision matrix can be compared and selected.

Following the data in [26], it is assumed that an education evaluation team will evaluate the teaching ability of four universities $A_{i}(i=1,2,3,4)$. After research, the group decided to evaluate the teaching ability of colleges and universities from the following five aspects: $G_{1}$ : teachers' educational level; $G_{2}$ : education expenditure; $G_{3}$ : scientific research achievements in the last ten years; $G_{4}$ : students' academic achievements; and $G_{5}$ : graduates' employment situation.

\subsection{Resolution Process}

Step 1: each expert in the evaluation team evaluates anonymously the five attributes of the teaching ability of four university representatives. Because experts come from different fields and have different professional backgrounds, in order to get more reasonable results, each expert gives the evaluation of each scheme $A_{i} \in A$ for each attribute $G_{j} \in G$, and at the same time, according to their familiarity with the attributes, each expert gives the credibility corresponding to the attribute value, deletes the duplicate data, and obtains a hesitation fuzzy decision matrix $H=\left(h_{i j}\right)_{m \times n}$; the specific decision matrix is shown in Table 1 . It is noteworthy that each assessment value contains the credibility and hesitant fuzzy element. For example, in the value $\{(0.7,0.4),(0.8,0.5),(0.4,0.6),(0.5,0.8)\}$ of $A_{1}$ under $G_{1}, 0.7,0.8,0.4$, and 0.5 represent credibility of the hesitant elements $0.4,0.5,0.6$, and 0.8 , respectively.

Then, we calculate a standardized evaluation matrix based on the confidence value, and the results are shown in Table 2.

From the correlation degree of the elements in the above attributes, we can see that the first element of the fourth attribute in scheme 2 deviates the most, that is, the hesitant fuzzy element $(0.8,0.3)$ is the deviation element; the first element of the first attribute in scheme 3 deviates the most, that is, the hesitant fuzzy element $(0.6,0.3)$ is the deviation element; the first element of the fifth attribute in scheme 3 deviates the most, that is, the hesitant fuzzy element $(0.8,0.3)$ is the deviation element. Therefore, we should feed back the deviated hesitant fuzzy elements of the four attributes and the comprehensive decision-making value of the corresponding attributes to the expert group and ask the expert group to reassess the credibility and decisionmaking value of the hesitant fuzzy elements involved. The reliability of deviating elements is adjusted according to equation (8).

Step 2: use the trustworthy hesitant fuzzy ensemble (RCIHFOWA) operator to aggregate the trustworthy hesitant fuzzy numbers corresponding to each attribute and get the comprehensive decision value of each attribute of each scheme, as shown in Table 3. Then, equation (6) $(\lambda=1)$ is used to calculate the difference $\bar{d}_{z g}\left(h_{i \times j}, h_{i \times j \times p}\right)$ between the integrated decisionmaking values of the uncertain fuzzy elements with credibility in each attribute and the corresponding attributes, as shown in Table 4 . 
TABLE 1: Initial hesitant fuzzy decision matrix with credibility.

\begin{tabular}{|c|c|c|c|c|c|}
\hline & $\mathrm{G}_{1}$ & $\mathbf{G}_{\mathbf{2}}$ & $\mathrm{G}_{3}$ & $\mathrm{G}_{\mathbf{4}}$ & $\mathrm{G}_{5}$ \\
\hline$A_{1}$ & $\begin{array}{c}\{(0.7,0.4) \\
(0.8,0.5) \\
(0.4,0.6) \\
(0.5,0.8)\}\end{array}$ & $\begin{array}{c}\{(0.7,0.5), \\
(0.5,0.6), \\
(0.3,0.7)\}\end{array}$ & $\begin{array}{c}\{(0.6,0.3) \\
(0.6,0.5) \\
(0.7,0.6)\}\end{array}$ & $\begin{array}{c}\{(0.7,0.4) \\
(0.8,0.6) \\
(0.7,0.7)\}\end{array}$ & $\begin{array}{c}\{(0.6,0.6), \\
(0.6,0.7), \\
(0.7,0.8)\}\end{array}$ \\
\hline $\mathbf{A}_{2}$ & $\begin{array}{c}\{(0.6,0.4) \\
(0.6,0.5) \\
(0.5,0.8)\}\end{array}$ & $\begin{array}{c}\{(0.4,0.7) \\
(0.6,0.8) \\
(0.6,0.9)\}\end{array}$ & $\begin{array}{c}\{(0.4,0.4), \\
(0.6,0.6) \\
(0.8,0.7) \\
(0.5,0.8)\}\end{array}$ & $\begin{array}{c}\{(0.8,0.3) \\
(0.7,0.5) \\
(0.8,0.8)\}\end{array}$ & $\begin{array}{c}\{(0.5,0.5), \\
(0.6,0.6), \\
(0.6,0.7),\}\end{array}$ \\
\hline $\mathbf{A}_{3}$ & $\begin{array}{c}\{(0.6,0.3) \\
(0.5,0.6) \\
(0.3,0.9)\}\end{array}$ & $\begin{array}{c}\{(0.8,0.4) \\
(0.3,0.6) \\
(0.4,0.9)\}\end{array}$ & $\begin{array}{c}\{(0.8,0.6) \\
(0.5,0.8) \\
(0.2,0.9)\}\end{array}$ & $\begin{array}{c}\{(0.8,0.5) \\
(0.7,0.6) \\
(0.2,0.8) \\
(0.3,0.9)\}\end{array}$ & $\begin{array}{c}\{(0.8,0.3) \\
(0.9,0.5), \\
(0.6,0.7)\}\end{array}$ \\
\hline $\mathbf{A}_{4}$ & $\begin{array}{c}\{(0.5,0.2) \\
(0.4,0.5) \\
(0.5,0.6)\}\end{array}$ & $\begin{array}{c}\{(0.6,0.4) \\
(0.6,0.6), \\
(0.1,0.9)\}\end{array}$ & $\begin{array}{c}\{(0.8,0.3) \\
(0.5,0.4) \\
(0.6,0.7) \\
(0.3,0.8)\}\end{array}$ & $\begin{array}{c}\{(0.5,0.3) \\
(0.4,0.5) \\
(0.5,0.8)\}\end{array}$ & $\begin{array}{c}\{(0.8,0.3), \\
(0.8,0.4), \\
(0.9,0.5)\}\end{array}$ \\
\hline
\end{tabular}

TABLE 2: Standardized hesitant fuzzy decision matrix with credibility.

\begin{tabular}{|c|c|c|c|c|c|}
\hline & $\mathrm{G}_{1}$ & $G_{2}$ & $\mathrm{G}_{3}$ & $\mathrm{G}_{4}$ & $\mathrm{G}_{5}$ \\
\hline$A_{1}$ & $\begin{array}{l}\{(0.7,0.4, \\
(0.8,0.5) \\
(0.4,0.6) \\
(0.5,0.8)\}\end{array}$ & $\begin{array}{l}\{(0.7,0.5, \\
(0.7,0.5) \\
(0.5,0.6) \\
(0.3,0.7)\}\end{array}$ & $\begin{array}{l}(0.6, \\
(0.7, \\
(0.7, c \\
\end{array}$ & $\begin{array}{l}.4), \\
6), \\
6), \\
7)\} \\
\end{array}$ & $\begin{array}{l}(0.6,0.7) \\
(0.7,0.8) \\
(0.7,0.8)\}\end{array}$ \\
\hline$A_{2}$ & $\begin{array}{l}\{(0.6,0 \\
(0.6,0 \\
(0.6,0 \\
(0.5,0 .\end{array}$ & $\begin{array}{c}\{(0.4, \\
(0.6, \\
(0.6, \\
(0.6,\end{array}$ & $\begin{array}{l}(0.6, \\
(0.8, \\
(0.5,0 \\
\end{array}$ & $\begin{array}{l}(0.7, \\
(0.8, \\
(0.8,\end{array}$ & $\begin{array}{l}(0.6, \\
(0.6, \\
(0.6,0 \\
\end{array}$ \\
\hline $\mathbf{A}_{3}$ & $\begin{array}{l}\{(0.6, \\
(0.6, \\
(0.5, \\
(0.3, c\end{array}$ & $\begin{array}{l}\{(0.8, \\
(0.8, c \\
(0.3, c \\
(0.4,0\end{array}$ & $\begin{array}{l}\{(0.8, \\
(0.8, \\
(0.5, \\
(0.2,\end{array}$ & $\begin{array}{l}\{(0.8, \\
(0.7, \\
(0.2, \\
(0.3,\end{array}$ & $\begin{array}{l}(0.9, \\
(0.9, \\
(0.6,\end{array}$ \\
\hline $\mathbf{A}_{4}$ & $\begin{array}{l}\{(0.5,0.2 \\
(0.4,0.5) \\
(0.5,0.6) \\
(0.5,0.6)\}\end{array}$ & $\begin{array}{l}\{(0.6,0.4 \\
(0.6,0.6) \\
(0.6,0.6) \\
(0.1,0.9)\}\end{array}$ & $\begin{array}{l}\{(0.8,0.3, \\
(0.5,0.4), \\
(0.6,0.7) \\
(0.3,0.8)\}\end{array}$ & $\begin{array}{l}\{(0.5,0.3, \\
(0.4,0.5) \\
(0.5,0.8) \\
(0.5,0.8)\}\end{array}$ & $\begin{array}{l}\{(0.8,0.3, \\
(0.8,0.4) \\
(0.9,0.5) \\
(0.9,0.5)\}\end{array}$ \\
\hline
\end{tabular}

TABLE 3: Values of attribute comprehensive decision after information integration.

\begin{tabular}{cccccc}
\hline & $\mathrm{G}_{1}$ & $\mathrm{G}_{2}$ & $\mathrm{G}_{3}$ & $\mathrm{G}_{4}$ & $\mathrm{G}_{5}$ \\
\hline $\mathrm{A}_{1}$ & 0.580 & 0.559 & 0.457 & 0.546 & 0.696 \\
$\mathrm{~A}_{2}$ & 0.513 & 0.805 & 0.666 & 0.722 & 0.597 \\
$\mathrm{~A}_{3}$ & 0.587 & 0.609 & 0.750 & 0.669 & 0.243 \\
$\mathrm{~A}_{4}$ & 0.427 & 0.663 & 0.588 & 0.554 & 0.413 \\
\hline
\end{tabular}

TABLE 4: Initial differences for each attribute.

\begin{tabular}{cccccc}
\hline & $\mathrm{G}_{1}$ & $\mathrm{G}_{2}$ & $\mathrm{G}_{3}$ & $\mathrm{G}_{4}$ & $\mathrm{G}_{5}$ \\
\hline $\mathrm{A}_{1}$ & 0.128 & 0.065 & 0.117 & 0.097 & 0.069 \\
$\mathrm{~A}_{2}$ & 0.078 & 0.071 & 0.100 & 0.263 & 0.070 \\
$\mathrm{~A}_{3}$ & 0.216 & 0.157 & 0.116 & 0.140 & 0.215 \\
$\mathrm{~A}_{4}$ & 0.164 & 0.110 & 0.179 & 0.189 & 0.075 \\
\hline
\end{tabular}

Step 3: assume that the expert group gives the threshold $\alpha=0.2$ of attribute association degree in advance. From Table 4, we can see that most of the attribute differences satisfy the consistency condition $\bar{d}_{z g}\left(h_{i \times j}, h_{i \times j \times p}\right)<0.2$, while the fourth attribute in scheme 2 and the first and fifth attributes in scheme 3 do not satisfy the consistency condition. Analysis of the five attributes of each element corresponding to the degree of difference is as follows:

$$
\begin{aligned}
& \left|h_{2 \times 4}-h_{2 \times 4 \times 1}\right|=0.402, \\
& \left|h_{2 \times 4}-h_{2 \times 4 \times 2}\right|=0.202, \\
& \left|h_{2 \times 4}-h_{2 \times 4 \times 3}\right|=0.098, \\
& \left|h_{2 \times 4}-h_{2 \times 4 \times 4}\right|=0.098 \\
& \left|h_{3 \times 1}-h_{3 \times 1 \times 1}\right|=0.313, \\
& \left|h_{3 \times 1}-h_{3 \times 1 \times 2}\right|=0.013, \\
& \left|h_{3 \times 1}-h_{3 \times 1 \times 3}\right|=0.287, \\
& \left|h_{3 \times 1}-h_{3 \times 1 \times 4}\right|=0.287 \\
& \left|h_{3 \times 5}-h_{3 \times 5 \times 1}\right|=0.457, \\
& \left|h_{3 \times 5}-h_{3 \times 5 \times 2}\right|=0.257, \\
& \left|h_{3 \times 5}-h_{3 \times 5 \times 3}\right|=0.257, \\
& \left|h_{3 \times 5}-h_{3 \times 5 \times 4}\right|=0.057 .
\end{aligned}
$$

The expert group reevaluated the attributes of the following schemes and obtained the following data: the first element of the fourth attribute $(0.8,0.3)$ in scheme 2 is changed to $(0.7,0.4)$; the first element of the first attribute $(0.6,0.3)$ in scheme 3 is changed to $(0.5,0.4)$; and the first element $(0.8,0.3)$ of the fifth attribute in scheme 3 is changed to $(0.7,0.4)$. The combined values of these four elements are $0.620,0.660$, and 0.620 , respectively. Then, the reliability of $l_{2 \times 4 \times 1}=0.6, l_{3 \times 1 \times 1}=0.3$, and $l_{3 \times 5 \times 1}=0.6$ is revised by equation (8), and the revised comprehensive values are $0.579,0.541$, and 0.601 , respectively. Substituting it into difference equation (6), we get the following results:

$$
\begin{aligned}
& \bar{d}\left(h_{2 \times 4}, h_{2 \times 4 \times 1}\right)=0.191 \prec 0.2, \\
& \bar{d}\left(h_{3 \times 1}, h_{3 \times 1 \times 1}\right)=0.184 \prec 0.2, \\
& \bar{d}\left(h_{3 \times 5}, h_{3 \times 5 \times 1}\right)=0.151 \prec 0.2 .
\end{aligned}
$$

The results show that the revised hesitant fuzzy elements satisfy the consistency condition. For the hesitation fuzzy set, the method not only reflects the difference of group opinion but also provides the basis for the decision-making process in the practical problems that need to compare and choose the best among various schemes.

5.2. Comparative Analysis. In [26], the credibility-induced hesitant fuzzy weighted average (CIHFWA) operator is used to compute the aggregated values. The result is shown in Table 5. 
TABLE 5: Values of attribute comprehensive decision in [26].

\begin{tabular}{cccccc}
\hline & $\mathrm{G}_{1}$ & $\mathrm{G}_{2}$ & $\mathrm{G}_{3}$ & $\mathrm{G}_{4}$ & $\mathrm{G}_{5}$ \\
\hline $\mathrm{A}_{1}$ & 0.334 & 0.289 & 0.307 & 0.424 & 0.453 \\
$\mathrm{~A}_{2}$ & 0.317 & 0.444 & 0.386 & 0.438 & 0.347 \\
$\mathrm{~A}_{3}$ & 0.252 & 0.291 & 0.365 & 0.320 & 0.376 \\
$\mathrm{~A}_{4}$ & 0.204 & 0.238 & 0.288 & 0.258 & 0.343 \\
\hline
\end{tabular}

Table 6: Initial differences for each attribute in [26].

\begin{tabular}{cccccc}
\hline & $\mathrm{G}_{1}$ & $\mathrm{G}_{2}$ & $\mathrm{G}_{3}$ & $\mathrm{G}_{4}$ & $\mathrm{G}_{5}$ \\
\hline $\mathrm{A}_{1}$ & 0.216 & 0.284 & 0.171 & 0.159 & 0.252 \\
$\mathrm{~A}_{2}$ & 0.236 & 0.369 & 0.257 & 0.193 & 0.259 \\
$\mathrm{~A}_{3}$ & 0.284 & 0.282 & 0.342 & 0.305 & 0.159 \\
$\mathrm{~A}_{4}$ & 0.227 & 0.293 & 0.226 & 0.278 & 0.089 \\
\hline
\end{tabular}

By using equation (6) $(\lambda=1)$, the difference between the integrated decision-making values of the uncertain fuzzy elements with credibility in each attribute and the corresponding attributes is shown in Table 6.

From Table 5, we can see that if the attribute association degree threshold is $\alpha=0.2$, then only 5 difference values are acceptable. If the consistency check process is carried out, most of the assessment information should be modified, which will make the efficiency very low. If the consistency check process is not carried out, then the agreement between individual opinion and collective opinion will be low, which will make the decision result unreliable. Compared with [26], the distance measure defined in this paper can consider the credibility of hesitant fuzzy elements in a comprehensive way, and the distance can figure out the elements which are far from the collective opinion efficiently. Additionally, the consistency check method in this paper can ensure a reliable decision result.

\section{Conclusion}

In this paper, the consistency test of uncertain fuzzy sets with credibility is studied, and the distance measure of uncertain fuzzy sets is introduced into the consistency test method. A method of consistency checking for reliability hesitant fuzzy sets based on distance measure is proposed, and its practicability and effectiveness are proved by an example.

This paper also has some limitations that it does not consider more complex decision-making situations, such as the decision makers have predefined preferences over the schemes, and that weights of attributes are unknown. In the future, we will focus on these complex situations in decision making and apply the proposed model in more practical problems.

\section{Data Availability}

No data were used to support this study.

\section{Conflicts of Interest}

The authors declare that they have no conflicts of interest.

\section{Acknowledgments}

This study was supported by the Major Project Plan of Philosophy and Social Science Application Research in Henan Universities (no. 2020-YYZD-02) and General Project of Humanities and Social Sciences Research of Henan Education Department (no. 2021-ZZJH-020).

\section{References}

[1] V. Torra, "Hesitant fuzzy sets," International Journal of Intelligent Systems, vol. 25, no. 6, pp. 529-539, 2010.

[2] M. Xia, Z. Xu, and N. Chen, "Induced aggregation under confidence levels," International Journal of Uncertainty, Fuzziness and Knowledge-Based Systems, vol. 19, no. 2, pp. 201-227, 2011.

[3] C. Y. Ruan, J. H. Yang, L. N. Han, and R. B. Liu, "A hesitant fuzzy decision-making method considering credibility and attribute priority," Operational Research and Management, vol. 25, no. 3, pp. 125-131, 2016.

[4] F. Herrera, E. Herrera-Viedma, and J. L. Verdegay, "A model of consensus in group decision making under linguistic assessments," Fuzzy Sets and Systems, vol. 78, no. 1, pp. 73-87, 1996.

[5] B. Dey, B. Bairagi, B. Sarkar, and S. K. Sanyal, "Group heterogeneity in multi member decision making model with an application to warehouse location selection in a supply chain," Computers\&Industrial Engineering, vol. 105, pp. 101-122, 2016.

[6] F. Herrera, E. Herrera-Viedma, and J. L. Verdegay, "A rational consensus model in group decision making using linguistic assessments," Fuzzy Sets and Systems, vol. 88, no. 1, pp. 31-49, 1997.

[7] J. G. Feng and C. P. Wei, "Group decision-making on language distribution assessment information and the consistency analysis of decision-making groups," Operations Research and Management Science, vol. 23, no. 5, pp. 120-127, 2014.

[8] F. J. Cabrerizo, S. Alonso, and E. Herrera-Viedma, "A consensus model for group decision making problems with unbalanced fuzzy linguistic information," International Journal of Information Technology \& Decision Making, vol. 8, no. 1, pp. 109-131, 2009.

[9] E. Herrera-Viedma, L. Martinez, F. Mata, and F. Chiclana, "A consensus support system model for group decision-making problems with multigranular linguistic preference relations," IEEE Transactions on Fuzzy Systems, vol. 13, no. 5, pp. 644658, 2005.

[10] E. Herrera-Viedma, F. S. Alonso, and F. Herrera, "A consensus model for group decision making with incomplete fuzzy preference relations," IEEE Transactions on Fuzzy Systems, vol. 15, no. 5, pp. 863-877, 2007.

[11] E. Szmidt and J. Kacprzyk, "A consensus-reaching process under intuitionistic fuzzy preference relations (p 837-852)," International Journal of Intelligent Systems, vol. 18, no. 7, pp. 837-852, 2010.

[12] Y. Xu, K. W. Li, and H. Wang, "Consistency test and weight generation for additive interval fuzzy preference relations," Soft Computing, vol. 18, no. 8, pp. 1499-1513, 2014.

[13] G. Bordogna, M. Fedrizzi, and G. Pasi, "A linguistic modeling of consensus in group decision making based on OWA operators," IEEE Transactions on Systems, Man, and Cybernetics-Part A: Systems and Humans, vol. 27, no. 1, pp. 126-133, 1997. 
[14] C. Fu and S.-L. Yang, "The group consensus based evidential reasoning approach for multiple attributive group decision analysis," European Journal of Operational Research, vol. 206, no. 3, pp. 601-608, 2010.

[15] Z. Meng, L. Ting, S. Jia, and M.-Y. Liu, "A method adjusting consistency and consensus for group decision-making problems with hesitant fuzzy linguistic preference relations based on discrete fuzzy numbers," Complexity, vol. 2018, Article ID 9345609, 17 pages, 2018.

[16] B. Farhadinia, Distance and Similarity Measures for Higher Order Hesitant Fuzzy sets, Elsevier Science Publishers B. V., Amsterdam, Netherlands, 2014.

[17] W. Zeng, Q. D. Li, and Q. Yin, "Distance and similarity measures between hesitant fuzzy sets and their application in pattern recognition," Pattern Recognition Letters, vol. 84, pp. 267-271, 2016.

[18] S. Zeng and Y. Xiao, "A method based on topsis and distance measures for hesitant fuzzy multiple attribute decision making," Technological and Economic Development of Economy, vol. 24, no. 3, pp. 969-983, 2018.

[19] Z. Xu and M. Xia, "Distance and similarity measures for hesitant fuzzy sets," Information Sciences, vol. 181, no. 11, pp. 2128-2138, 2011

[20] Z. Xu and M. Xia, "On distance and correlation measures of hesitant fuzzy information," International Journal of Intelligent Systems, vol. 26, no. 5, pp. 410-425, 2011.

[21] D. Li, W. Zeng, and J. Li, "New distance and similarity measures on hesitant fuzzy sets and their applications in multiple criteria decision making," Engineering Applications of Artificial Intelligence, vol. 40, pp. 11-16, 2015.

[22] D. Li, W. Zeng, and Y. Zhao, "Note on distance measure of hesitant fuzzy sets," Information Sciences, vol. 321, pp. 103115, 2015.

[23] M. Zhang, T. Zheng, W. Zheng, and L. Zhou, "Interval-valued pythagorean hesitant fuzzy set and its application to multiattribute group decision-making," Complexity, vol. 2020, Article ID 1724943, 26 pages, 2020.

[24] H. Wang, X. Wang, and L. Wang, "Multicriteria decision making based on archimedean bonferroni mean operators of hesitant fermatean 2-tuple linguistic terms," Complexity, vol. 2019, Article ID 5705907, 19 pages, 2019.

[25] X. Qi, J. Zhang, and C. Liang, "Multiple attributes group decision-making approaches based on interval-valued dual hesitant fuzzy unbalanced linguistic set and their applications," Complexity, vol. 2018, Article ID 3172716, 22 pages, 2018.

[26] C. Y. Ruan, A Hesitant Fuzzy Decision-Making Method Based on Credibility and Priority, South China University of Technology, Guangzhou, China, 2016. 